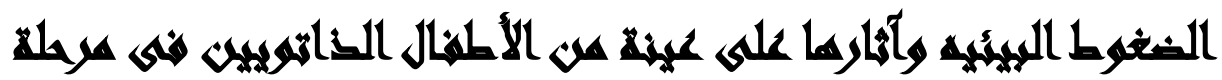 الطمنولا المريحرة
}

[9]

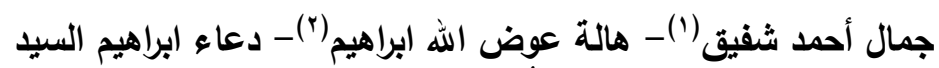

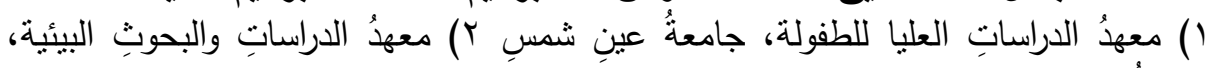
جامعةُ عينِ شمسِ الرساتِ

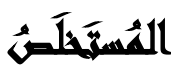

استهرفت الدراسة بوجة عام الكثف عن تأثير الضغوط البيئيه على الأطفال الذاتويين

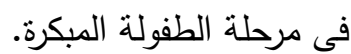

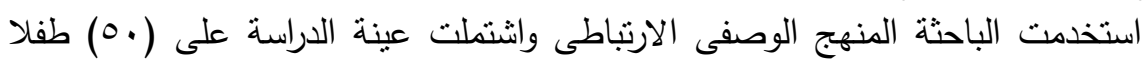

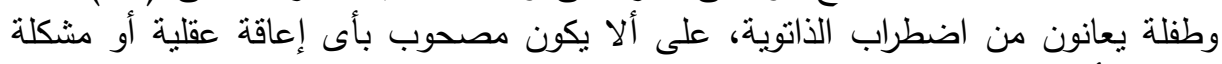

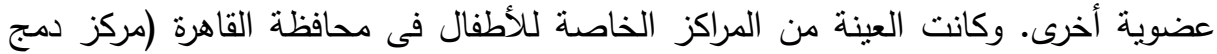

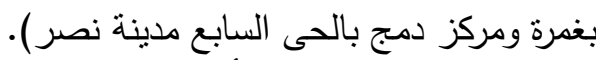

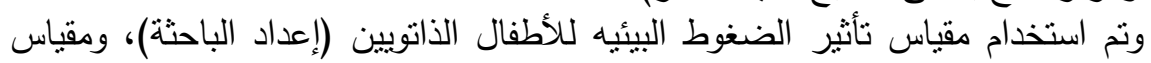

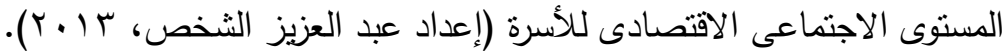

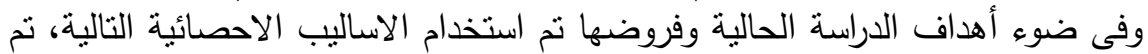

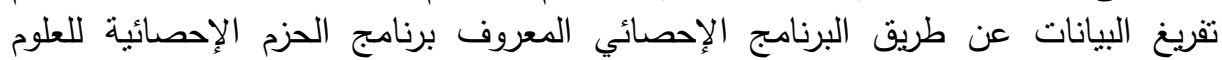

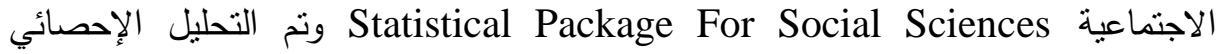

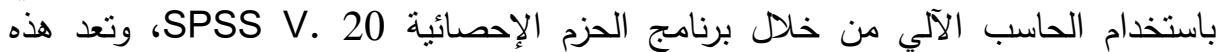
الخطوة - تفريغ البيانات- خطوة تمهيدية لتبويب البيانات.

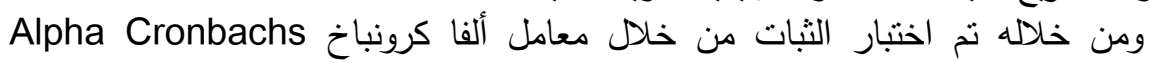

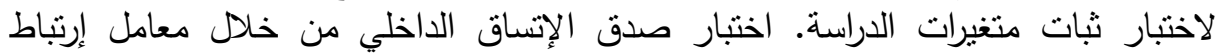

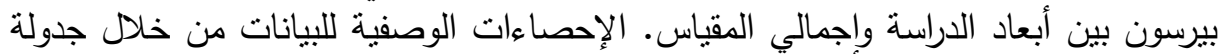

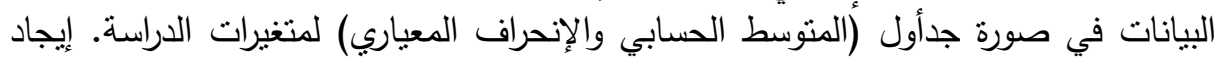

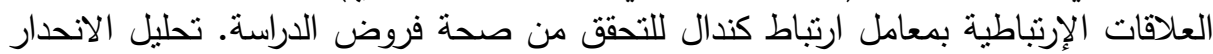

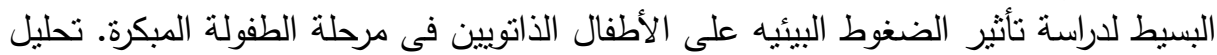
الانحدار المتعدد لدراسة تأثثر الضغوط البير عليئيه على الأطفال الذاتويين فى مرحلة الطفولة الطئلة

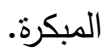


وقد أسفرت الدراسة عن مجموعة من النتائج أنه لاتوجد علاقة ذات دلالة احصائية بين

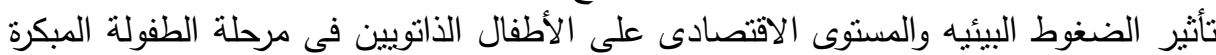

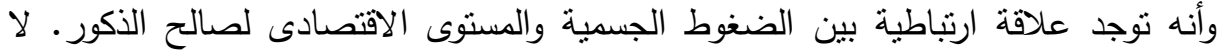
توجد علاقة ذات دلالة احصائية بين تأثنير الضغوط الضين البيئيه والمستوى الاجتماعى على الألئي الطفال

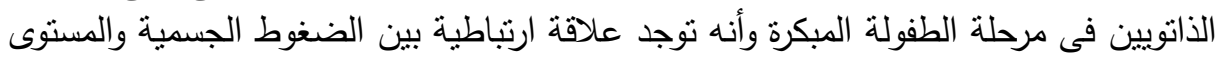

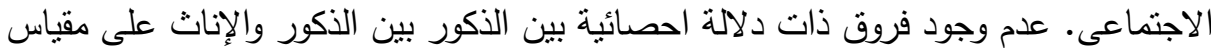

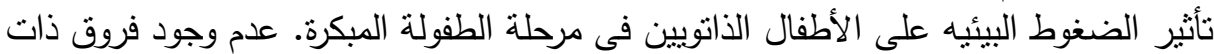

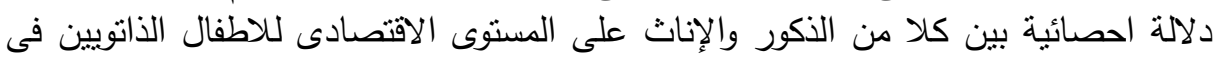

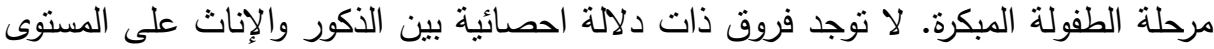

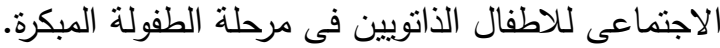
يوصى البحث باجراء مزيد من الدراسات على الأطفال الذاتويين وخاصة فيما يتعلق

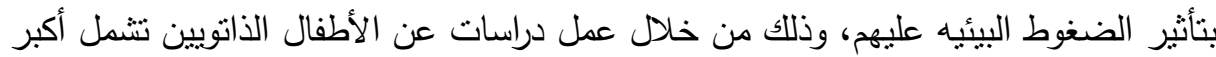

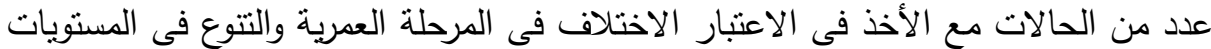

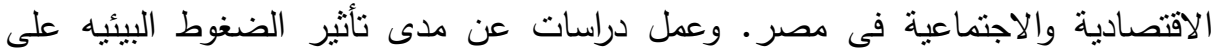
الأطفال الذاتويين وخاصة فى مرحلة الطفولة المبكرة. وعمل دراسات في الإلى العوامل البيئيه

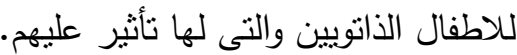
الكلمات الدالة: الضغوط البيئيه، الاضطراب الذابن الذاتوى، الطفولة المبكرة.

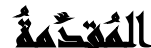

تعد السنوات الأولى من حياة الطفل (مرحلة الطفولة) من أهم مراحل نموه حيث بداية تكوين القدرات الفكرية والمعرفية والتعليمية وفيها يشتد قابلية الطفل للتأثر بالضغوط البيائيه خاصة فى مرحلة الطفولة المبكرة، وان أكثر الأثخاص المضطربين قد يكونوا تعرضوا للصدمات نفسية إثثاء مرحلة الطفولة بصفة عامة، والطفولة المبكرة بصفة خاصة نتيجة الضغوط البيئيه المحيطة بهم لذلك يجب تهية البيئة التى يعيش فيها الطفل وتوفير المناخ النفسى السوى أثناء مراحل نموه الأولى يؤدى إلى نثأة جيل سوى خإلى من الاضطراب، يعود

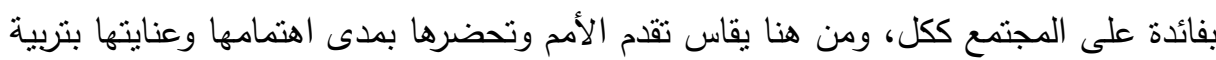

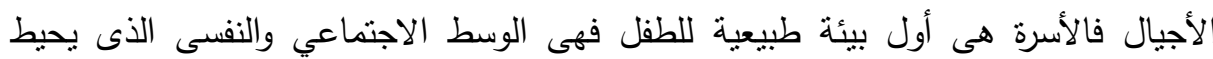
بالطفل فهى أساس تكوين وتحديد شخصيه، يتعلم فيها الثخص السلوكيات التى تجعل له دور

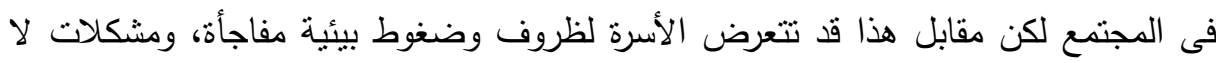

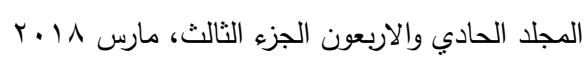


يمكن التخلص منها خاصة الأسرة التى يوجد بها طفل ذاتوى، ومع التقدم العلمى خلال ثورة

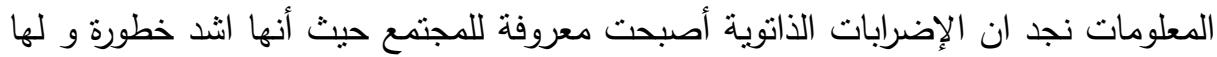
تأثنير كبير على شخصية الطفل فى العديد من الجوانب بحيث تحدث تأخر عام. (سهى أحمد

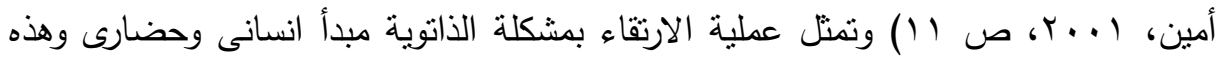
المشكلة لا تزال بحاجة إلى جهذ كبير حتى ينالوا الذاتوبين قدر كبير من الرعاية الإنسانية

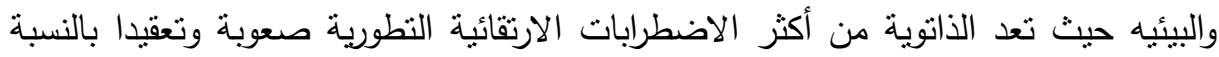
للطفل ويتميز هذا النوع من الاضطرابات بالانسحاب للاخل والانغلاق على الذات فبذللك يرفض الطفل الذاتوى أى نوع من الاقتراب الخارجى خاصة اذا ازدادت الضغوط الإس البيئيه

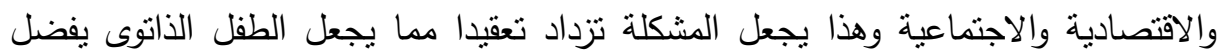
التعامل مع الأشياء الغير طبيعية أكثر من تعامله مع الأشخاص المحيطين به والذانوية

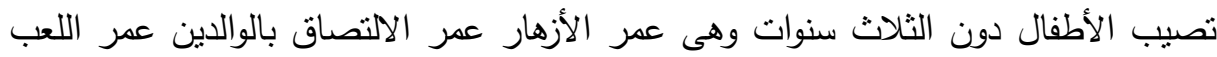
الجماعي والتفاعلي والبدء فى تكوين بيئة ثانية وهى بيئة الأصدقاء والساحة والثارع ولكن النان

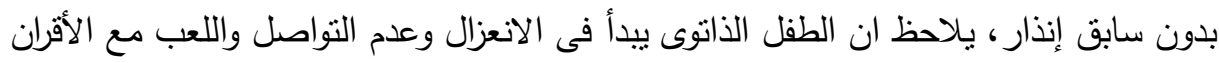

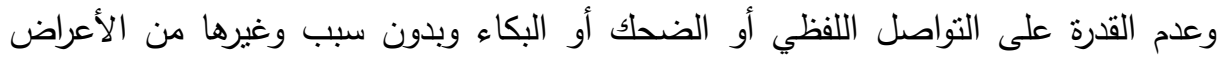
التى تجعل الاهتمام بهذه الثريحة اهنمام ضرورى ومهم ومن أجل تحقيق تلك الأغراض

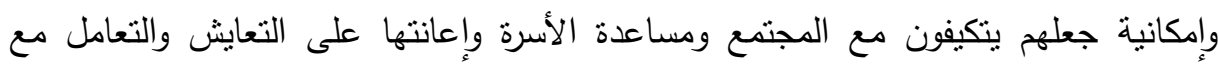

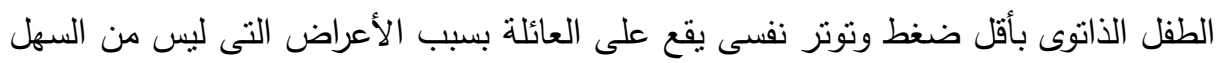

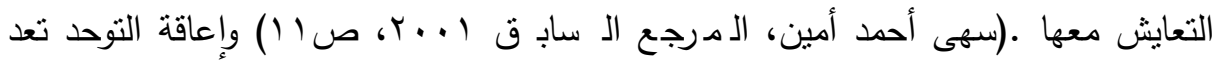

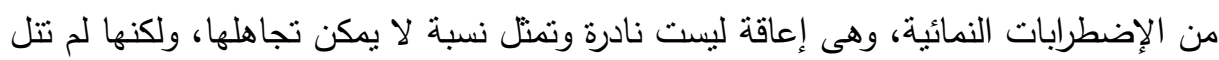
حظها من الاهنمام على المستوى البحثى في الدول النامية، فى حين أننا نجد اهنماماً متزايداً فى الدول المنقدمة، وقد زاد الاهتمام نسبيا بهذه الفئة فى البلاد العربية خلال السنوات العشرة

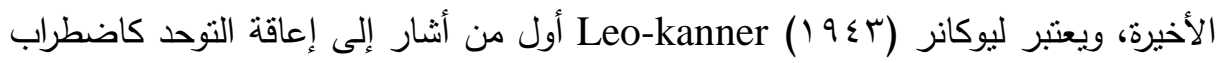

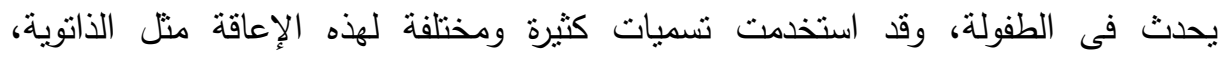
والإجترارية، والتوحدية، والأويتسية، والإنغلاق الذاتى (الإنشغال بالذات)، والذهان الذاتوى، وفصام الطفولة ذاتى التركيب، والإنغلاق الطفولى، وذهان الطفولة لنمو (أنا) غير سوي.

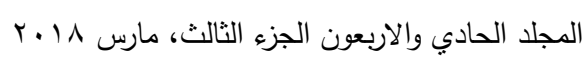


(محمد خطاب، 0 . . Y، ص 9) والبعض من الضغوط يأتى من التفاعل بين الجانبين أى

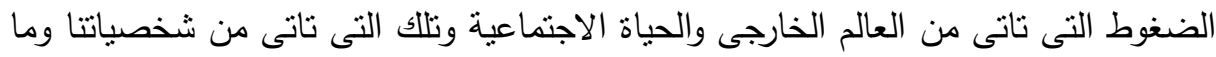
نتصف به من صحة بدنية ومن خصائص نفسية أو من قدرات وسمات تعدنا للاستجابة السليمة أو غبر السليمة لما يأتينا من ضغوط خن خارجية، اذ من الطبيعى أن كل واحد منا عندما

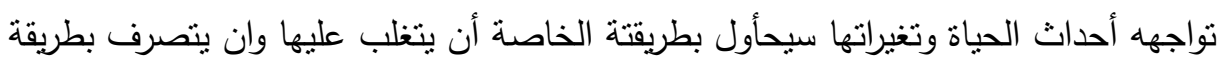
ما، ومن الطبيعى أيضا ان تختلف الطرق التى نسلكها لتحقيق ذلك بعضنا يحب المواجهة

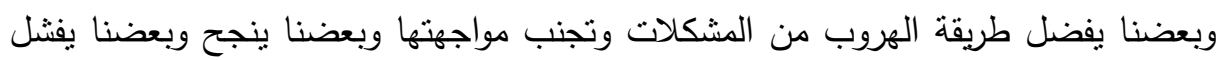
فى تطوير التصرف الملائم حيال هذه الضغوط الخارجية والمنطلبات الاجتماعية ومنطلبات

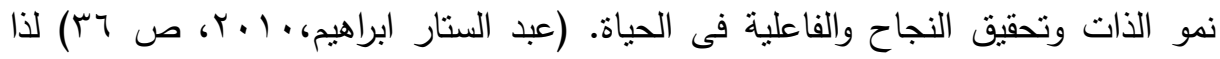
يتضح ضرورة معرفة تأثثر الضغوط البيئيه من الناحية الفزيقية والاجتماعية على الأطفال الذاتوبين فى مرحلة الطفولة المبكرة ولما كان هنالك ندرة فى الدراسات العربية والاجنيية فى

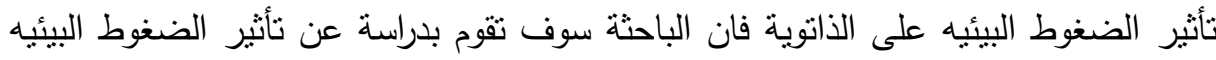

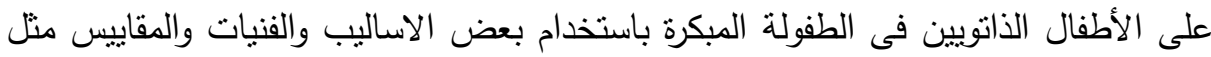
تأثثير الضغوط البيئيه من الناحية الفزيقية والاجتماعية .

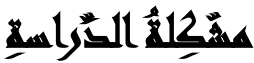

تأتي مشكلة الدراسة من نتائج الدراسات السابقة حيث تعدد المشكلات للأطفال الذاتويين التي تشمل عدة جوانب منها الانمائية والمعرفية واللغوية والحركية والاجنماعية والسلوكية ومن أهم مشكلات الذانوية هي الضغوط البيئيه لذاللك يجب ان يتلائم مع بيئته الفزيقية والنفسية

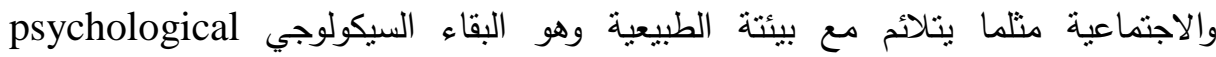
.survival وغالبا الأطفال الذاتويين يجدون صعوبة نتيجة الضغوط البيئيه بجانب صعوبه فى معرفه احتياجاتهم كما ان هناك ضغوط بيئية ومتغيرات بيئية لها علاقه بمدى تقدم الطفل الذاتوى حيث نجد ندرة الدراسات المتعلقة بالضغوط البيئيه لدى الأطفال الذاتويين سواء أكانت هذه

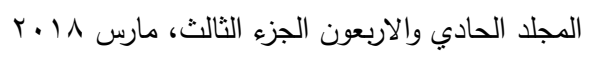


الدراسات عربية أو أجنبية وللضغوط البيئيه تأثير على الأطفال الذاتويين وخاصه فى مرحلة الطفوله المبكرة على اختلاف درجتها ولها تأثنير على الجوانب الآتيه (النمو الجسمي - النمو

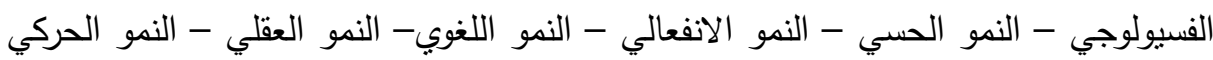

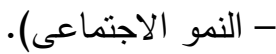

مدى شيوع وانتشنار الاضطراب الأتوى: معدل الانتشار فى المجتمعات -اختلفت نتائج الدراسات التى تحدد نسبة الانتشار للاضطراب الذاتوى فيرى ايسون 1991 ان التضارب فى معدلات الانتشار يرجع إلى البلا الذى تتم فية الدراسة وإلى اختلاف الدلالات التشخصية وقد يكون السبب فى الاختلاف فى عمر الأطفال موضوع الدراسة. (نادية ابو السعود، ؟ . . ץ).

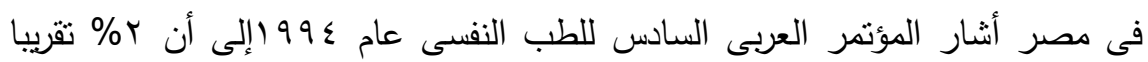
من السكان الذين يصنفوا كمعاقين عقليا أو لديهم اضطرابات سلوكية أو انفعالية يكونو

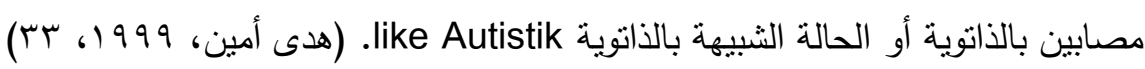
ملى انتشار الاضطراب الأتوى بين الأكور والاناث: يحدث الاضطراب الذاتوى بمعدل اربع مرات أكثر فى الذكور عن الاناث ولا يذكر سبب مفهوم إلى الآن فى ظهور

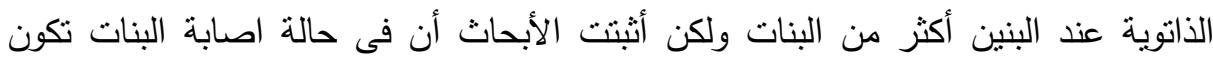
إعاقتهم أكثر صعوبة وخطر وتكون درجة ذكائهر منخفضة جدا عن غيرهم من البنين الذين

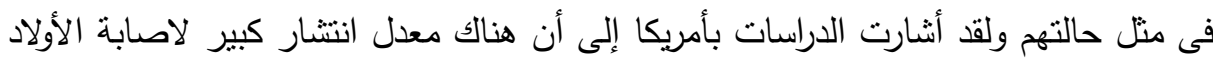

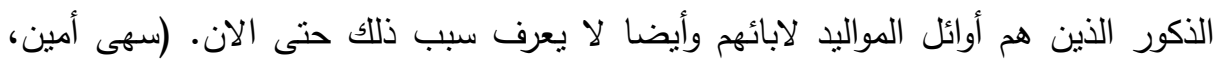
(1) 6 T. T)

معدل الانتشار بالنسبة للمستوى الاجتماعى والاقتصادى: كان للأحد عشر طفلا الذين وصفهم كانر بأنهم يعانون من الاضطراب الذاتوى ينتمون إلى عائلات متعلمة وذكية حققت

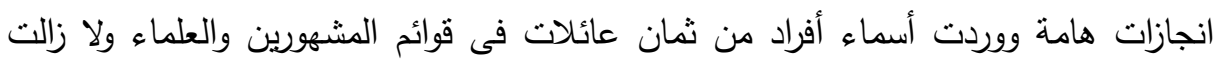

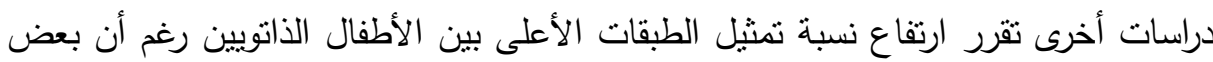
التقارير الحديثة لم تستطيع أن تؤكد ذلك. 
عبر التغيرات الأخيرة تزايدت نسبة الحالات بين الطبقات الاقتصادية والاجتماعية الأدنى وقد يرجع ذلك إلى نزايد الوعي والزمالة وزيادة العاملين فى مجال الصحة العقلية بين هذه الطبقات وذلك فإن الاحتمال كبير بأن تكون زيادة النسبة بين الطبقات الأعلى هى نئ نتيجة

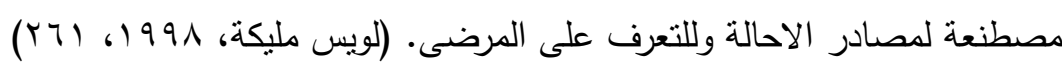

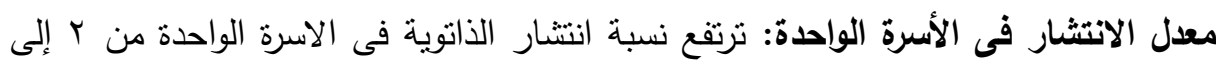

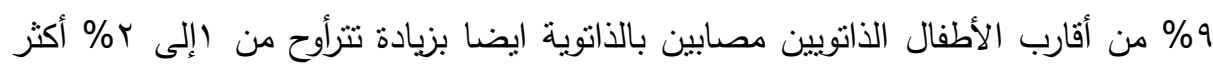

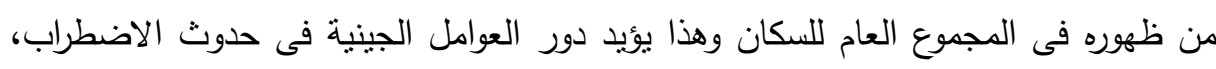
ترتفع نسبة ظهور الاضطرابات الاجتماعية والصعوبات المعرفية واللغوية لاى اقارب الأطفال المصابين بالذاتوية وتعتبر نسبة الانتشار الذاتوية بين التوائم المنطابقة اعلى بالمقارنة بالتوائم

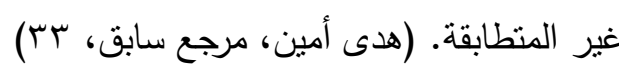

\section{أسريلا المهيه}

ما مدى العلاقة بين تأثير الضغوط البيئيه والمستوى الاقتصادى على الأطفال الذاتويين

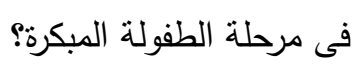
ما مدى العلاقة بين تأثير الضغوط البيئيه والمستوى الاجتماعى على الأطفال الذانويين

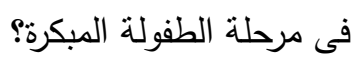
• ما مدى العلاقة بين كلا من (الذكور والاناث) على المستوى الاقتصادى على الأطفال

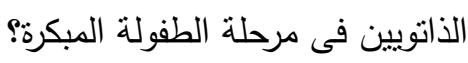
ما مدى العلاقة بين كلا من (الذكور والإناث) على المستوى الاجتماعى على الأطفال

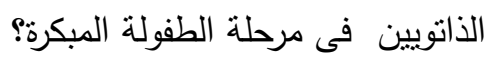
• ما مدى العلاقة بين الذكور والإناث على المستوى الاجتماعى للاطفال الذاتويين فى مرحلة الطفولة المبكرة؟ ملى المبه 


\section{التراسايت الساريه}

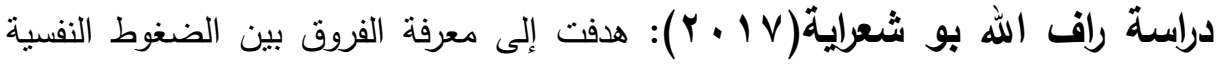
وعلاقتها بالتوافق الأسري، بالإضافة إلى التعرف على الفروق بين الضغوط النفسية والتوافق

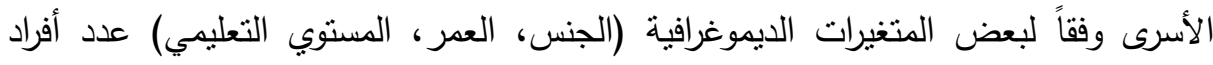

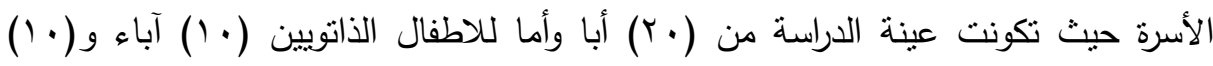
أمهات. تكونت أدوات الدراسة من مقياس الضغوط النفسية لدى الأطفال الذاتوبين، ومقياس

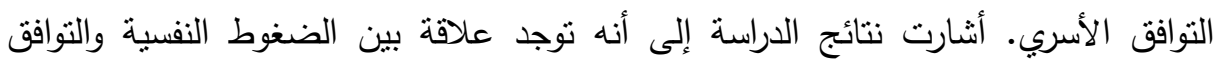
الأسرى لدى والدى الأطفال الذاتويين، توجد فروق بمستوي الضغوط النفي النفسية بين آباء وأمهات

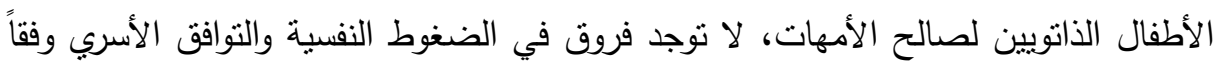

$$
\text { للمتغيرات الديموغرافية (عمر الوالدين، المستوي التعليمي، وعدد أفراد الأسرة). }
$$

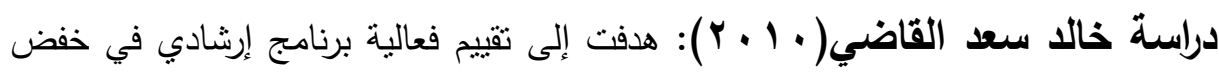

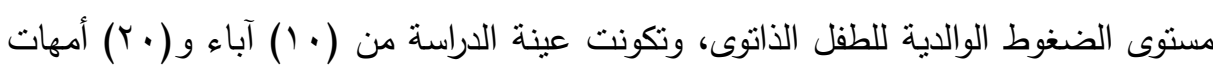

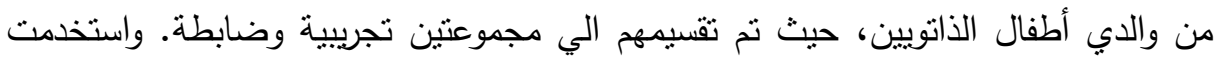
أدوات منها مقياس جيليام لتتخيص الذاتوية، ومقياس الضغوط الوالدية إعداد الباحث، فئ،

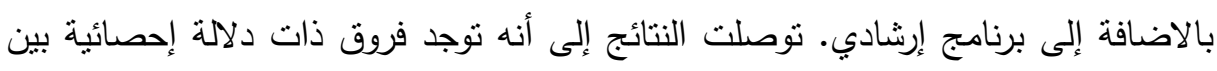

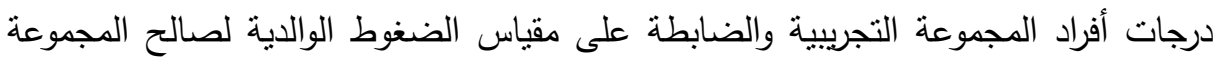
التجريبية. دراسة (2008) Hall : هدفت إلى اختبار السلوك التكيفي للطفل الذاتوي، وشبكات الدعم

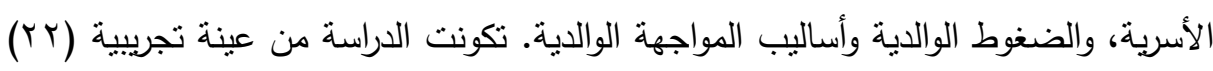

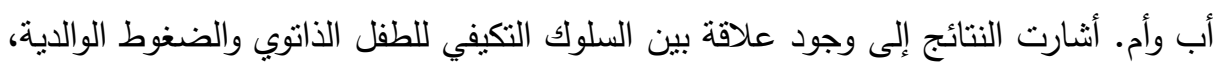

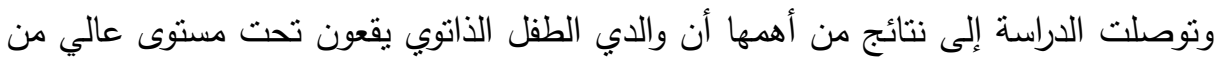
الضغوط، والكثير من العائلات ترى بأن شبكات الدعم الاسري غير ذان ذات جدوى، وفئ وفعاليتها

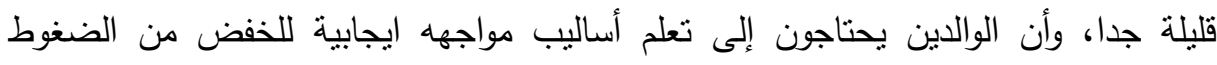


دراسة (2004) Hart : هدفت إلى التعرف على مستوى الضغوط النفسية والاكتئاب والقلق

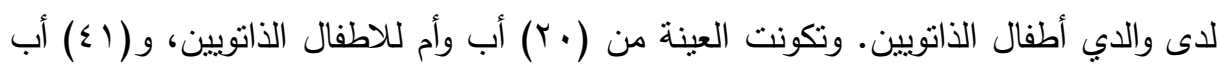

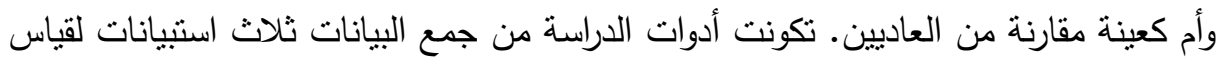
كل من الضغوط النفسية والقلق والاكتئاب. وتوصلت الدراسة إلى نتائج من أهمها أن آباء

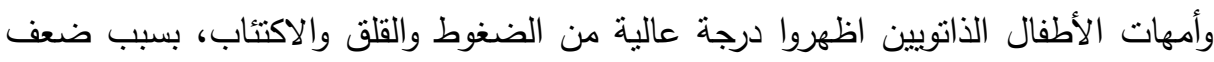
الدعم الاجتماعي وبعض العوامل الثخصية وتأثثر الطفل الذاتوي على باقي أفراد الاسرة .

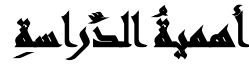

أما عن أهمية الدراسة؛ فيمكن القول بأن لكل دراسة أكاديمية أهميتها التي تدفع الباحثون

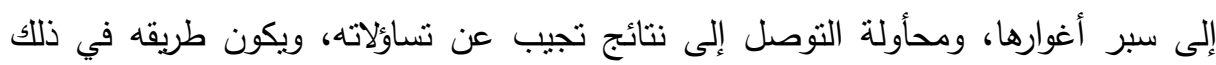
الأدوات المختلفة للبحث العلمي ومناهجه، مع استخدامها بطريقة علمية موضوعية منهجية، والبحث العلمي بسعى إلى تحقيق هدفين رئيسيين أولهما نظري، والثاني نطبيقى. أما الهدف

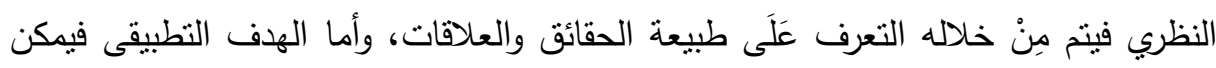
الاستفادة منه فى المراكز والمؤسسات العلاجية والاخصائين الاجتماعين والنفسين والقائمين على رعاية الأطفال الذاتوبين وأسرهم بوضع خطة للعلاج عَلَى أساس سليم. (عبد الهادي الهاعين ولفين

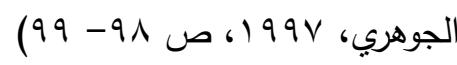

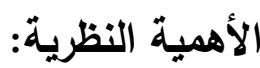

• تحديد مفهوم الضغوط البيئيه لدى الأطفال الذاتوبين فى مرحلة الطفولة المبكرة.

• • اثراء الجانب المعرفى حول الذانوية لدى الأطفال فى مرحلة الطفولة المبكرة.

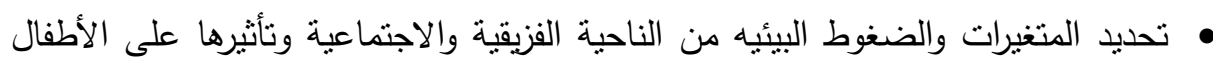

في مرحلة الطفولة المبكرة.

• تحديد المفاهيم المختلفة للذاتوية ومدى انتشارها وأغراضها وأسبابها وتتخصيها.

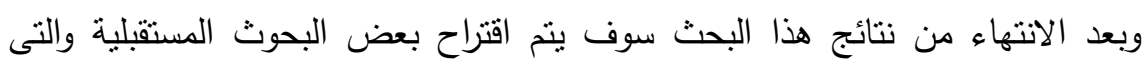
يمكن اجراؤها فى هذا المجال. 
الأهمية التطبيقية:

• قلديم نماذج علمية داعمة للأسرة لتقليل الضغوط البيئيه الفزيقية والاجتماعية على الأطفال الذاتويين فى مرحلة الطفولة المبكرة. • مساعدة الاخصائيين الاجتماعيين والنفسيين المتعاملين مع الطفل الذاتوى فى مرحلة الطفولة المبكرة لتقليل من الضغوط البيئيه.

وباستخلاص النتائج الهامة لهذة الدراسة يمكن التوصل إلى بعض التوصيات التطبيقية والتى يمكن الاستفادة بها فى هذا المجال وبخاصة المتعاملين مع الطفل الذاتوى من اعداد دورات تدريبية للمتعاملين مع هؤلاء الأطفال، بالاضافة إلى اعداد برامج لتوعيتهم بهذه

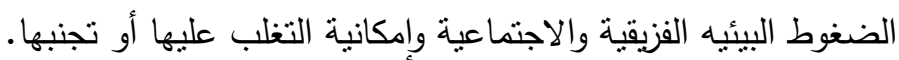

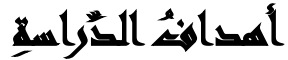

•التعرف على الضغوط البيئيه الفزيقية والاجتماعية التي لها تأثير على الأطفال الذاتويين في مرحلة الطفولة المبكرة. إلقاء الضوء على مدي تأثثر الضغوط البيئيه الأسرية على الأطفال الذاتوبين من حيث المستوي الاقتصادى الاجتماعي ومدى معرفة الأسرة بالإعاقة الذاتوية واتجاهات الوالدين فى التعامل مع الطفل الذاتوي فى مرحلة الطفوله المبكرة. • الكثف عن مدي العلاقة بين كلا من الضغوط البيئيه المحيطة بالطفل الذاتوي ومدى فره تقدمها.

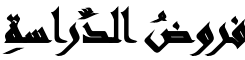

• توجد علاقة ذات دلالة احصائية بين تأثير الضغوط البيئيه والمستوى الاقتصادى لدى الأطفال الذاتويين فى مرحلة الطفولة المبكرة. • توجد علاقة ذات دلالة احصائية بين تأثير الضغوط البيئيه المستوى الاجتماعى لاى الأطفال الذاتويين فى مرحلة الطفولة المبكرة. 
مجلة العلوم البيئية

معهد الدراسات والبحوث البيئية - جامعة عين شمس ليه

•توجد فروق ذات دلالة احصائية بين كلا من (الذكور والإناث) على المستوى الاقتصادى

لدى الأطفال الذاتويين فى مرحلة الطفولة المبكرة.

توجد فروق ذات دلالة احصائية بين كلا من (الذكور و الإناث) على المسنوى الاجتماعى لده

لدى الأطفال الذاتويين فى مرحلة الطفولة المبكرة.

توجد فروق ذات دلالة إحصائية بين كل من الذكور والإناث على المستوى الاجتماعي

على الأطفال الذاتويين في مرحلة الطفولة المبكرة.

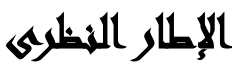

الضغوط البيئية: لا يزال مفهوم الضغوط البيئية حتى الآن مفهوما غامضا بل ومحيرا، فليس هنالك تعريف محدد متفق عليه، وعلى الرغم من ذلك يدركه الرجل العادى والمختص و

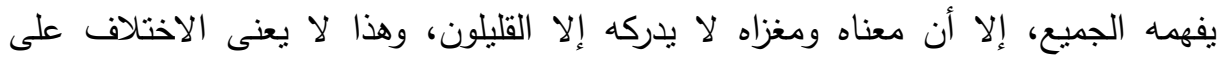
التعريف فقط وإنما الاختلاف على المصطلح نفسه والمصطلحات البديلة فى مواقف مختلفة، وهذا ما يدعوا إلى التعرف إلى المصطلحات الأخرى التى تثير فى مجموعها إلى مفهوم الضغوط فى الأوساط العلمية. (1azrus 1966-12:24)

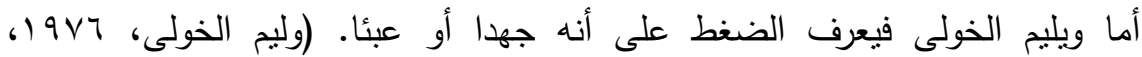
(ะTru الضغط قد ينشأ من داخل الفرد نفسه نتيجة الأزمات التي يعيشها ويسمى ضغط داخلي،

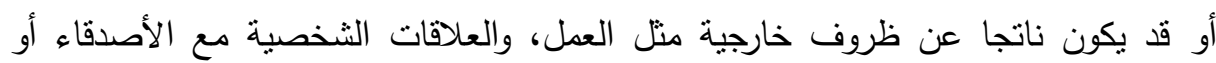
شريك الحياة أو موت عزيز أو موقف صادم ويسمى ضغط خارجي (الغرير وأبو أسعد،

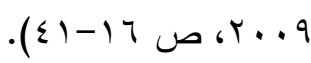
أما التعريف الإجرائي للضغوط البيئيه هو تعرض الفرد لمواقف ضاغطة فى البيئة يدرك الفرد من خلال (تقييم معرفي) أن قدراته وامكانيته لا تقوى علي مواجهة هذه الضغوط فيختل التوازن فيحأول الفرد أن يعأود نوافقه مع البيئة فى إطار يسعى الفرد فيه لإعادة توافقه، تجتاحه حالة من التوتر وعدم التوازن أعراضها نفسية وفسيولوجية وهي استجابات الضغوط وتختلف 
مستويات الضغوط من فرد إلى آخر وذاللك طبقا إلى مجموعة من العوامل كطبيعة الضغوط وخبرة الفرد وخصائص الفرد وشخصيته والمستوى الثقافي وغيرها ... إلخ. نظرية التوافق بين الفرد والبيئة: هذه النظرية ترى أن الضغوط تكون نتيجة اختلال التوازن بين الفرد والبيئة التي يوجد فيها؛ أبي أن الضغوط تنتج من سوء التوافق بين الفرد والبيئة، وينتج سوء التوافق أو حسن التوافق من جانبين أساسين هما: مدى الانسجام بين قدرات الفرد

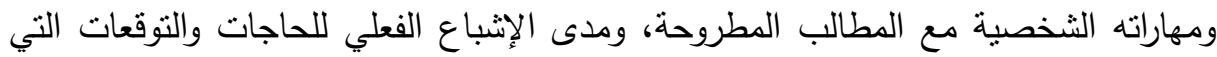

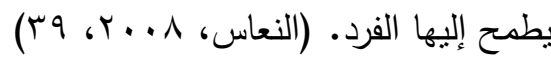
الاضطراب الأتوى: ان هذا المرض اضطراب الذاتوية من الاعاقات التى تحبط بها كثثر من الغموض والألغاز المحيرة حيث استحوذ على اهتمام كثير من العلماء لتفسير أسباب حدوثه وقد تعددت الأبحاث العلمية للوصول إلى سبب محدد ولكن كل التفسيرات كانت تعبر عن وجهات نظر وتخصصات أصحابها ومنهم من أكد أنها أسباب اجتماعية ونفسية وأسرية لهنية

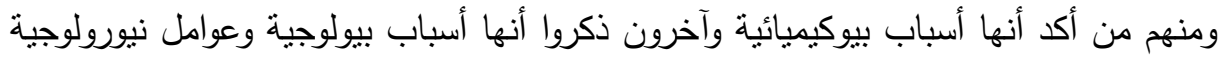

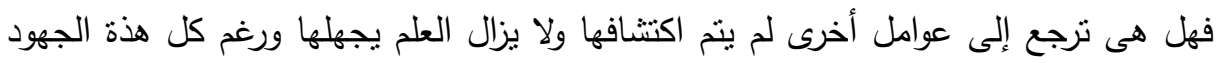
والمحأولات إلا أنه لم يتم التوصل إلى عرامل آترى عوامل محددة لتقسير هذا النوع من الاعاقات. (سوزان

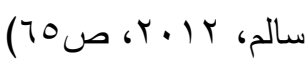

الذاتوية autism هي خلل فى الجهاز العصبى يوثز على مختلف نواحى النمو المتمثلة فى

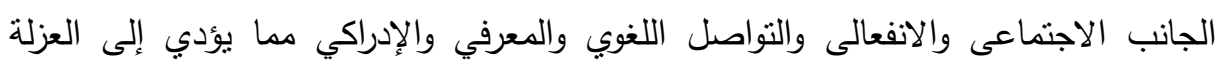
والانسحاب من المجتمع المحيط به ويظهر اضطراب الذانوية منذ الولادة وحتى سن الثالثة وقد يكون لاى الذاتوبين قدرات خاصة فى بعض الجوانب مثل القدرات الحسابية. (سوسن محمد

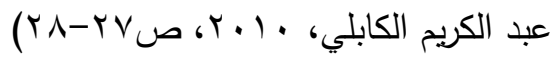
أما التعريف الإجرائى للانوية فهو نوع معقد من الاضطرابات الارتقائية ويحدث خلل وظيفي للمخ ويوقف النمو الادراكى الحسي الانفعالي وعدم القدرة على التواصل اللفظي وغير الإسط اللفظي وغالبا يحدث فى السنوات الأولى من عمر الطفل ويصاحب ذاللك انطواء وانغلاق مع التع التعات الذات وصعوبة التوافق مع التغيرات البيئيه. 
نظرية المنشأ النفسي للاصابة بالذاتوية: إن اكتثاف الذاتوية حديث العهد منذ بـ 9 ام ويعد ليو كانر أول من وضع تصنيفا بحيث كان الاعتقاد السائد قديما بأن عدم دراية الوالدين بانه

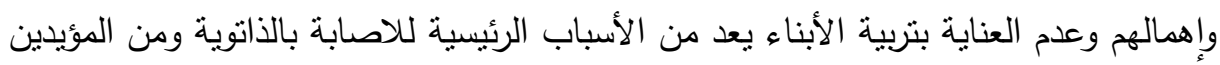
لهذا التفسير برونو بلتهابم (Bruno Bettelheim) حيث كان يقوم بنقل الأطفال الذاتويين للعيش مع عائلات بديلة كأسلوب لعلاج الإصابة بالذاتوية وقد كان ذلك يبعث عن الارتياح

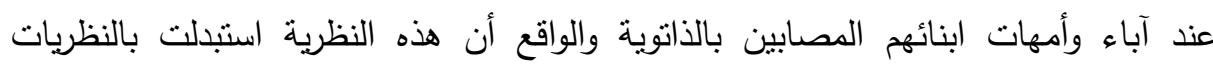
البيولوجية القائمة على وجود خلل فى بعض أجزاء المخ نتيجة لعوامل بيولوجية منل الجينات

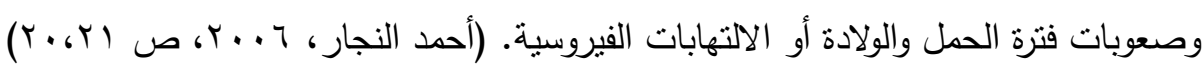
الطقولة المبكرة: إن الكثير من علماء النفس قد أجمعوا على أهمية مرحلة الطفولة المبكرة وأنها فى غاية الأهية، فمدرسة التحليل النفسي مثلا ركزت على هذة المرحلة تركيزا بالغا ففرويد (freud) رأى أن شخصية الفرد تتكون من خلاال الخمس سنوات يعتبرها مرحلة النمو

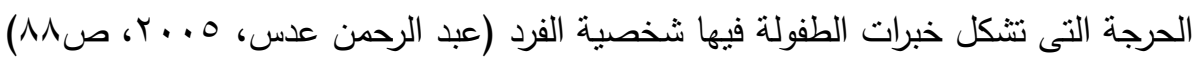

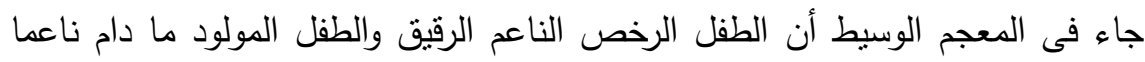
رخصا، والجمع طفولة وأطفال. (عبد الرحمن محمد السيد، نظريات الثخصية، 1991 199، ( التعريف الإجرائي للطفولة المبكرة هي الفتره من سن (r - T) سنوات وهي فترة بعتمد

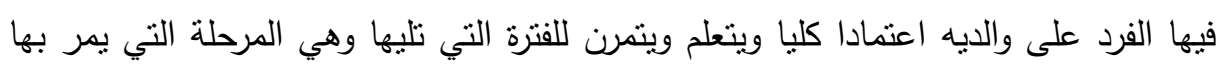
الثخص عندما يكون طفلا.

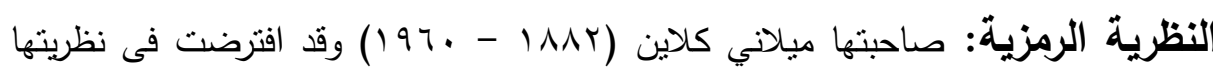
هذه أن تكنيك التداعي الحر هو القاعدة الأساسية فى تحلل الكبار، بواسطة إيضاح أهمية الرمزية، والتى تسمح للطفل أن يُسقط على الاثياء الموجودة فى بيئة تخيلاته وأوجه قصره

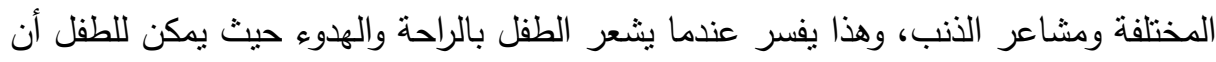

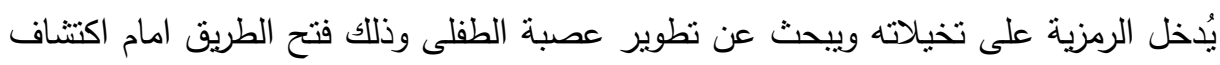
المحللة لعالم التخيلات، فقد كثف عن عدد ضخم من التخيلات السادية والفمية الثرجية

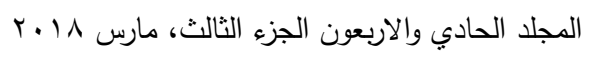


والبولية بالاضافة إلى التخيلات اللبدية والابستموفلية. (نفين مصطفى زيور، 991)،

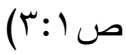

\section{المنهمجُ المستخصئ.}

استخدم الباحثون المنهج الوصفي الارتباطي وتعريف المنهج الوصفي الارتباطي يهنم

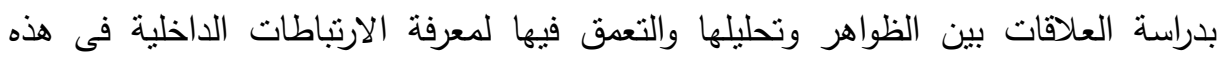
الظواهر وكذللك الارتباطات الخارجية بينها وبين الظواهر الأخرى (عبد الرحمن عدس؛ كايد

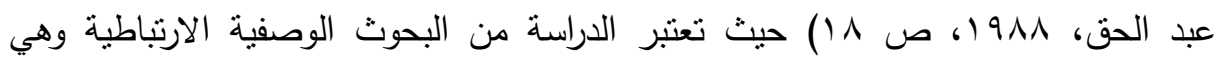

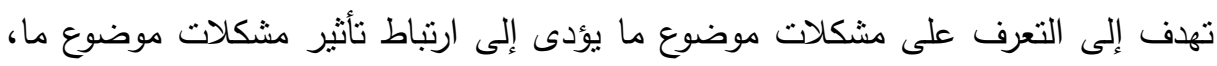

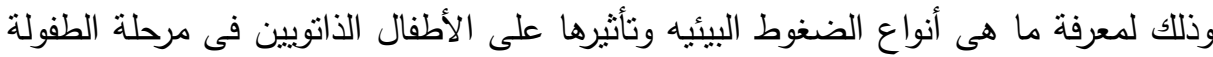

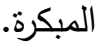
أدواتُ جمع البياناتِ: اعتمد الباحثون في بحثهم عَلَى المادة العلمية النظرية والميدانية ومصادرهما ما يلي: • مصادر جمع المادة العلمية النظرية تمنلت في: القرآن الكريم، والكتب، والرسائل الجامعية، والمقالات، والقواميس والمعاجم، والإنترنت. • مصادر جمع المادة العلمية الميدانية: تطلبت طبيعة الدراسة استخدام عدة أدوات لجمع البيانات، وقد تم اختيارها بما يتتاسب وأهداف الدراسة وفروضها، ونوع البيانات التي يود الباحث الوصول إليها، بالإضافة إلى الإمكانات المتوافرة وطبيعة الظروف المحيطة

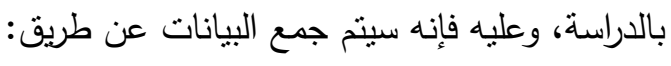

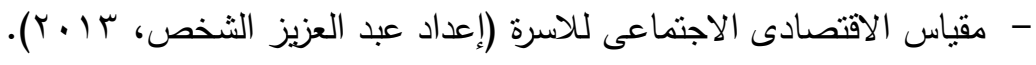
- مقياس تأثير الضغوط البيئيه على الأطفال الذاتويين (إعداد الباحثة). وصف المقياس: يتكون المقياس فى صورته الأولية من (VY) عبارة مقسمة إلى (T) إبعاد

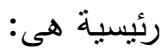


ا ـ الأعراض الجسمية: هى مجموعة الآثار الجسمية التى تعكس انخفاض مستوى طاقة آباء

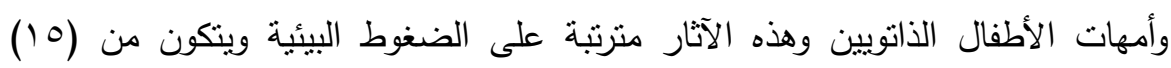
عبارة. r. الأعراض البيئية: المرتبطة بإصابة الطفل بالذاتوية وهى مجموعة من الآثار النفسية التى

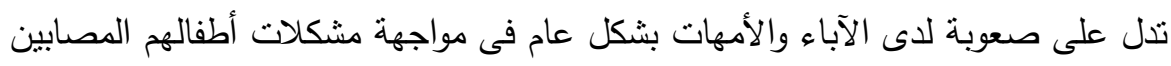

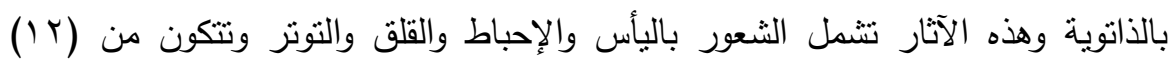
عبارة. r. الضغوط البيئية الناتجة عن مشكلات التواصل للطفل الذاتوى: هى حالة من الضيق النفسى الثديد عند آباء وأمهات الأطفال الذاتوبين بسبب عدم قدرة أطفالهم على التعبير عما بداخلهم سواء من خلال الكلام أو الإيماءات وتتكون من (• (1) عبارة.

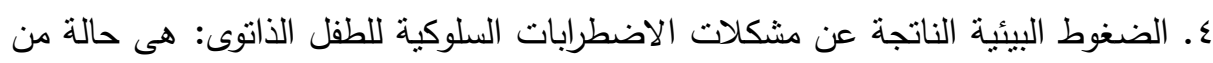
القلق عند آباء وأمهات الأطفال الذاتويين بسبب عدم سواء السلوك الناتج عن اضطراب الإبه

$$
\text { الذاتوية وتتكون من (lv) عبارة. }
$$

ه. الضغوط البيئية الناتجة عن القصور فى المهارات الاجتماعية للطفل الذاتوى: هى حالة

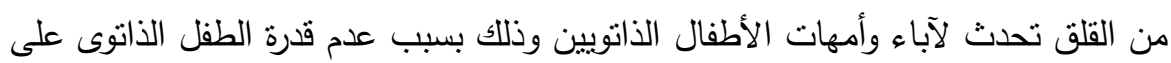

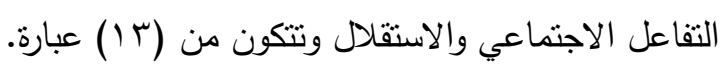

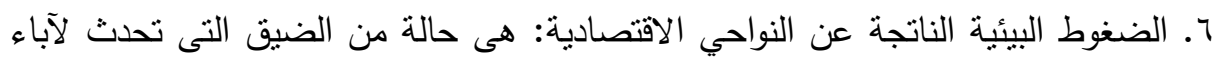
وأمهات الأطفال الذاتوبين بسبب أن منطلبات رعاية الإبن المصاب بالذاتية التوية كثثبرة ومكلفة

$$
\text { تفوق قدرتهم المادية وتتكون من (0) عبارات }
$$

ثبات المقياس: للتحقق من ثنات المقياس استخدمت الباحثة معادلة ألفا كرونباخ (Alpha Cronbach)، ويوضح الجدول التالي معاملات الثبات الناتجة باستخدام هذه هئه المعادلة. 
جدول (1) (1) تبات العبارات لأبعاد المقياس

\begin{tabular}{|c|c|c|}
\hline معامل ثبات ألفا & عدد العبارات & أبعاد المقياس \\
\hline$\cdot, \wedge 79$ & 10 & الضغوط الجسمية \\
\hline • AYT & IT & الضغوط النفسية \\
\hline$\cdot, V \backslash Y$ & 1. & الضغوط التواصلية \\
\hline$\cdot, \wedge \varepsilon 1$ & IV & الضغوط السلوكية \\
\hline$\cdot, V \leqslant \varepsilon$ & $1 \pi$ & الضغوط الاجتماعية \\
\hline., $0 \vee 7$ & 0 & الضغوط الاقتصادية \\
\hline., $91 \mathrm{~V}$ & $V Y$ & إجمالى المقياس \\
\hline
\end{tabular}

يتضـح من الجدول السابق أن قيم معاملات الثبات لأبعاد المقياس جميعها قيم مرتفعة

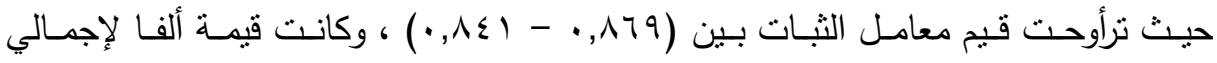

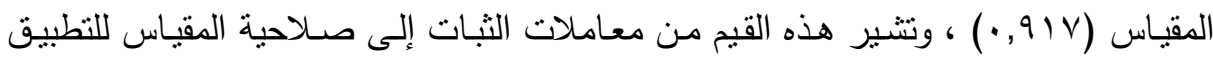
وإمكانية الاعتماد على نتائجه والوثوق به. ثبات الاتساق الاخلى: بحساب الاتساق الداخلى للاختبار ، وذلك من خلادال حساب معاملات

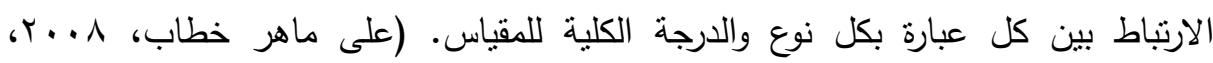

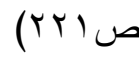
صدق الإتساق الاخلي: بحساب صدق الإتساق الداخلي ومعامل الارتباط المصحح لكل محور بإجمالي المقياس لحساب الصدق كالآتي: جدول (r): ثبات العبارات لأبعاد المقياس

\begin{tabular}{|c|c|c|c|}
\hline معامل التصحيح & معامل الصدق & & آبعاد المقياس \\
\hline \multirow{2}{*}{$\cdot, \wedge \wedge$} & $(* *) \cdot, \vee \wedge \wedge \wedge$ & معامل ارتباط بيرسون & \multirow{2}{*}{ الضغوط الجسمية } \\
\hline & $\cdot, \ldots 1$ & الدلالة المعنوية & \\
\hline \multirow{2}{*}{ • } & $($ ***) $)$, ६०น & معامل ارتباط بيرسون & \multirow{2}{*}{ الضغوط النفسية } \\
\hline & $\cdot, \cdots 1$ & الدلالة المعنوية & \\
\hline \multirow{2}{*}{$\cdot, \uparrow \wedge$} & $(* *) \cdot, 01$. & معامل ارتباط بيرسون & \multirow{2}{*}{ الضغوط التواصلية } \\
\hline & $\cdot, \cdots 1$ & الدلالة المعنوية & \\
\hline \multirow{2}{*}{$\cdot,\rceil \wedge$} & $(* * *) \cdot$, VOr & معامل ارتباط بيرسو & \multirow{2}{*}{ الضغوط السلوكية } \\
\hline & $\cdot, \cdots 1$ & الدلالة المعنوية & \\
\hline \multirow{2}{*}{$\cdot, 9$} & $(* * *) \cdot, \wedge) \cdot$ & معامل ارتباط بيرسون & \multirow{2}{*}{ الضغوط الاجتماعية } \\
\hline & $\cdot, \cdots 1$ & الدلالة المعنوية & \\
\hline \multirow{2}{*}{$\cdot, 9$. } & $(* *) \cdot, \Lambda) Y$ & معامل ارتباط بيرسون & \multirow{2}{*}{ الضغوط الاقتصادية } \\
\hline & $\cdot, \cdots 1$ & الدلالة المعنوية & \\
\hline
\end{tabular}

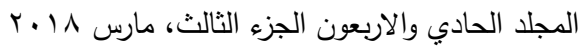


من الجدول السابق لصدق الاتساق الداخلي السابق للمقياس نجد أن قيم معامل الارتباط

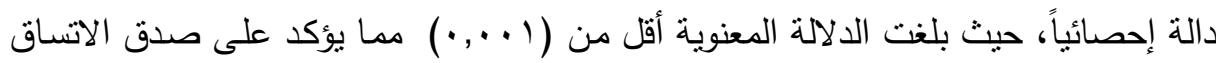

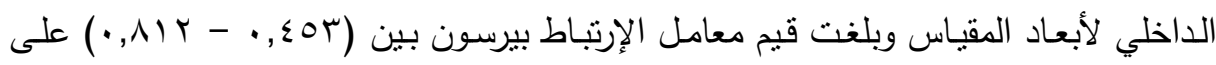

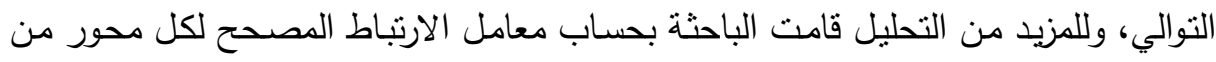

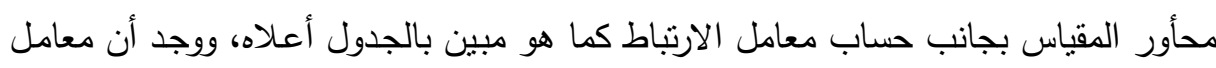

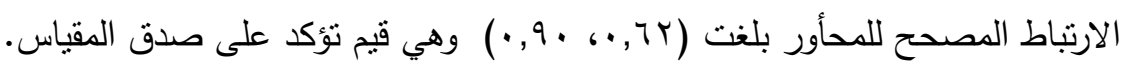

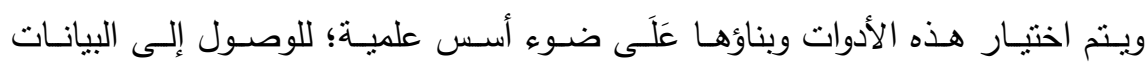
المطلوبة، وبالتالي تحقيق أهداف البحث.

\section{عبنةٌُ الكِّراسة}

تتكون عينة الدراسة من (•0) طفلا وطفلة (0 طفل، و و ط طفلة) يعانون من الذاتوية،

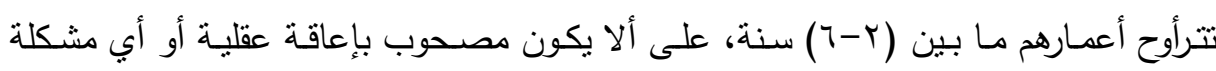
عضوية، وكانت العينة من مركز دمج الأطفال بغمرة ومركز دمج الأطفال بالحى السابع مدينة نصر بالقاهرة.

طريقة التطبيق: مقياس المستوى الاقتصادى الاجتماعى ينم تطبيق المقياس على الأطفال الذاتويين فى مرحلة الطفولة المبكرة من خلاال سؤال آباء وأمهات الأطفال أو القائمين عليهح

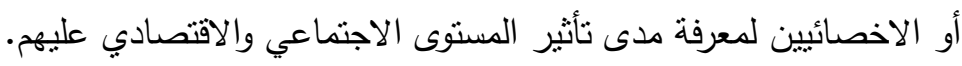

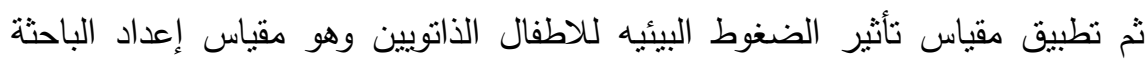
يتكون من ست أبعاد مختلفة لتأثير الضغوط والأبعاد هى الجسميه والاجتماعية والنفسية والتواصلية والاقتصادية والسلوكية وذلك بتطبيق المقياس على الأطفال الذاتوبين فى مرحلة

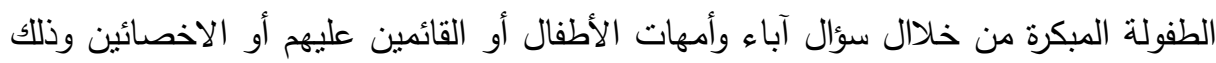
من أجل معرفة تأثثر الضغوط البيئيه بأبعادها المختلفة عليهم. 


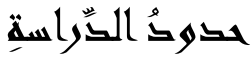

كالحدود الموضوعية: وتتمتل في دراسة الضغوط البيئيه وآثارها على عينة من الأطفال الذاتويين فى مرحلة الطفولة المبكرة.

ه الحدود المكانية: وتتمثل فى المراكز الخاصة بمحافظة القاهرة، لتطبيق المقاييس على عينة من الأطفال الذاتويين من الذكور و الاناث فى مرحلة الطفولة المبكرة. ه الحدود الزمنية: وهى الفترة التى نم فيها تطبيق المقاييس على عينة من الأطفال الذاتويين المعرضين لتأثير الضغوط البيئيه بأنواعها فى مرحة الطفولة المبكرة. > الحدود البشرية: وتتمثل في الأطفال الذاتويين وآبائهم وأمهاتهم والقائمين عليهره والاخصائيين الاجتماعيين.

أساليب المعالجة الاحصائية: فى ضوء الدراسة الحالية وفروضها نم استخدام الاساليب الاحصائية التالية: تم تفريغ البيانات عن طريق البرنامج الإحصائي المعروف برنامج الحزم الإحصائية للعلوم الاجتماعية Statistical Package For Social Sciences ونت التحليل

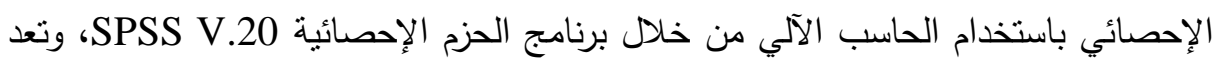

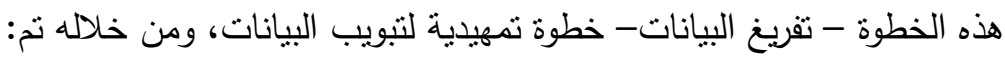
ا-اختبار الثبات من خلال معامل ألفا كرونباخ Alpha Cronbachs لاختبار ثنبات متغيرات الدراسة. r-اختبار صدق الإتساق الداخلي من خلال معامل إرتباط بيرسون بين أبعاد الدراسة وإجمالي

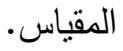

r-الإحصاءات الوصفية للبيانات من خلال جدولة البيانات في صورة جداول (المتوسط

$$
\text { الحسابي والإنحراف المعياري) لمتغيرات الدراسة. }
$$

ع - إيجاد العلاقات الإرتباطية بمعامل ارتباط كندال للتحقق من صحة فروض الدراسة.

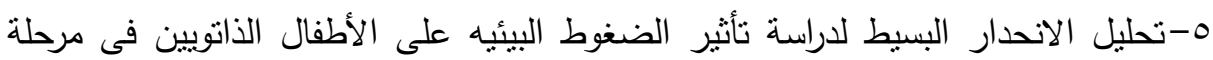
الطفولة المبكرة.

$$
\text { المجلد الحادي والاربعون الجزء الثالث، مارس \1 بـr }
$$


ج-تحليل الانحدار المتعدد لدراسة تأثير الضغوط البيئيه على الأطفال الذاتوبين فى مرحلة الطفولة المبكرة.

حساب ثبات وصدق لمقياس تأثير الضغوط البيئيه على الأطفال الذاتويين: قياس الاعتمادية (الثبات والصدق للاستيـان): ثبات المقياس. ثبات الاتساق الد/خلى. قام الباحث بحساب الاتساق الداخلى للاختبار ، وذلك من خلاال حساب معاملات الارتباط بين كل عبارة بكل نوع والدرجة الكلية للمقياس. (على

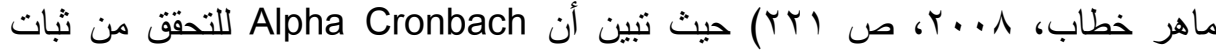
المقياس استخدمت الباحثة معادلة (ألفا كرونباخ) قيم معاملات الثبات لأبعاد المقياس جميعها

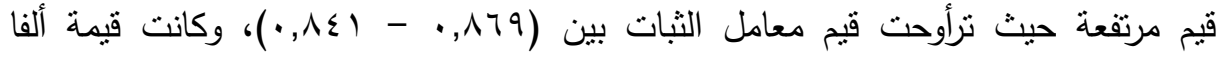

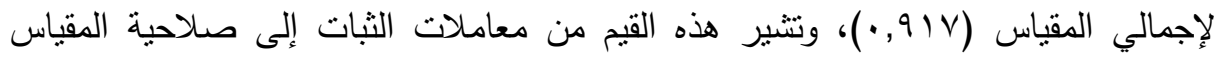
للنطبيق وإمكانية الاعتماد على نتائجه والوثوق به.

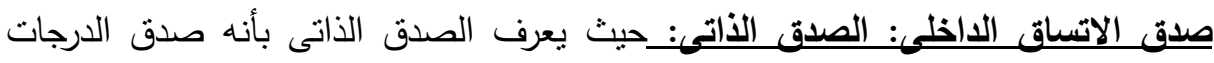

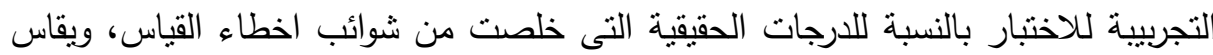
الصدق الذاتى بحساب الجذر التربيعى لكل نوع وكذلك الدرجة الكلية. (فؤاد السيد، 9Av، صץ +ـ ؛ قامت الباحثة باجراء الجانب الميدانى بعد اتمام امتحانات الجانب النظرى فى شهر

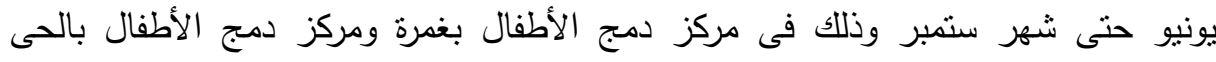

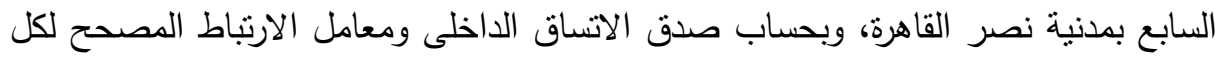
محور بإجمالى المقياس لحساب الصدق - فقد نجد أن قيم معامل الارتباط دالة إحصائياً، حيث بلغت الدلالة المعنوية أقل من (1 . ., •) مما يؤكد على صدق الاتساق الداخلي لأبعاد

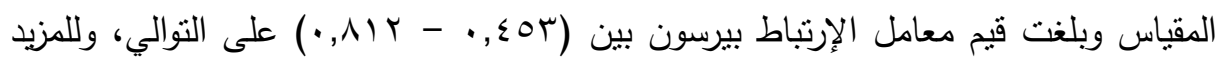
من التحليل قامت الباحثة بحساب معامل الارتباط المصحح لكل محور من محاور المقياس بجانب حساب معامل الارتباط كما هو مبين بالجدول أعلاه، ووجد أن معامل الارتباط

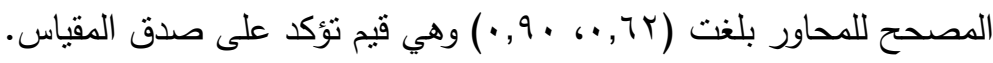




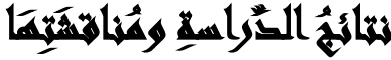

1- لاتوجد علاقة ذات دلالة احصائية بين تأثنير الضغوط البيئيه والمستوى الاقتصادي على فهل

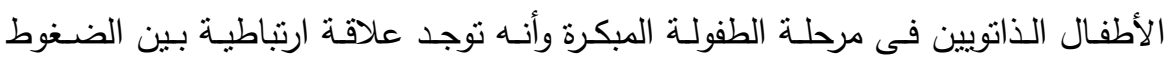

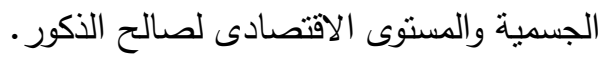

r-لاتوجد علاقة ذات دلالة احصائية بين تأثنير الضغوط البيئيه والمسنوى الاجتماعي على الإلى

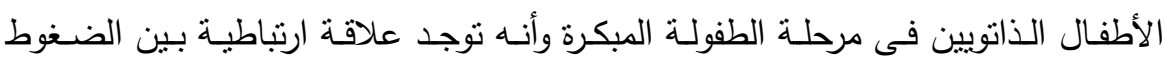

$$
\text { الجسمية والمستوى الاجنماعي. }
$$

r-عدم وجود فروق ذات دلالة احصائية بين الذكور بين الذكور والإناث على مقياس تأثير الضغوط البيئيه على الأطفال الذاتويين فى مرحلة الطفولة دله المبكرة.

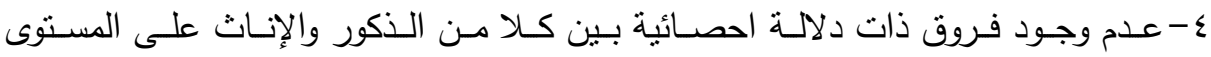
الاقتصادي للأطفال الذانويين فى مرحلة الطفولة المبكرة. ه-لاتوجد فروق ذات دلالة احصائية بين الذكور والإناث على المستوى الاجتماعى للاطفال الذاتويين فى مرحلة الطفولة المبكرة. عرض تفسير ومناقشة نتائج الفرض الأول: ينص الفرض الأول على أنه نوجد علاقة ذات

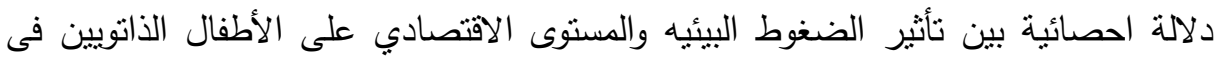
مرحلة الطفولة المبكرة. وللتحقق من صحة الفرض تم حساب معامل الارتباط والدلالة المعنوية لتوضيح العلاقة الارتباطيـة بين تأثير الضـغوط البيئيسه والمستوى الاقتصـادي للاطفـال الذاتويين في مرحلـة

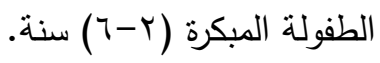


مجلة العلوم البيئية

معهد الدراسات والبحوث البيئية - جامعة عين شمس ليه

جدول(ץ): العلاقة الارتباطية بين تأثير الضغوط البيئيه والمستوى الاقتصادي للاطفال الذاتوبين في مرحلة الطفولة المبكرة لإجمالي عينة الدراسة الطئة

\begin{tabular}{|c|c|c|}
\hline المستوى الاقَتصادى & \multicolumn{2}{|c|}{ المتغيرات } \\
\hline$\cdot, 1 \wedge \varepsilon-$ & معامل الارتباط & \multirow{2}{*}{ الضغوط الجسمية } \\
\hline$\cdot, r$ & الدلالة المعنوية & \\
\hline$\cdot, \cdot \wedge \varepsilon$ & معامل الارتباط & \multirow{2}{*}{ الضغوط النفسية } \\
\hline$\cdot, 7$ & الدلالة المعنوية & \\
\hline$\cdot, \cdot \lambda 1$ & معامل الارتباط & \multirow{2}{*}{ الضغوط التواصلية } \\
\hline$\cdot, 7$ & الالالة المعنوية & \\
\hline$\cdot, Y M$ & معامل الارتباط & \multirow{2}{*}{ الضغوط السلوكية } \\
\hline$\cdot, 1$ & الدلالة المعنوية & \\
\hline$\cdot, \cdot V$ & معامل الارتباط & \multirow{2}{*}{ الضغوط الاجتماعية } \\
\hline$\cdot, 7$ & الالالة المعنوية & \\
\hline., 199 & معامل الارتباطّ & \multirow{2}{*}{ الضغوط الاقتصادية } \\
\hline$\cdot, r$ & الدلالة المعنوية & \\
\hline$\cdot, .7$ & معامل الارتباط & \multirow{2}{*}{ إجمالي المقياس } \\
\hline$\cdot, \mathrm{V}$ & الدلالة المعنوية & \\
\hline
\end{tabular}

يوضح الجدول السابق نتائج العلاقة الإرتباطية بين الضغوط البيئيه والمستوى لإنية

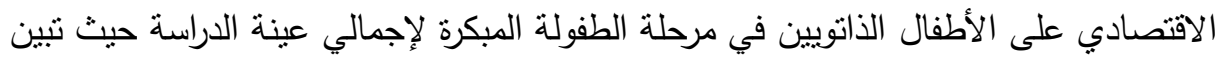

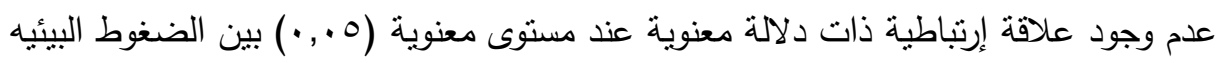
والمستوى الاقتصادي على الأطفال الذاتوبين في مرحلة الطفولة المبكرة لإجمالي عينة الدراسة. جدول (§): العلاقة الارتباطية بين تأثير الضغوط البيئيه والمستوى الاقتصادي على الإلى الأطفال

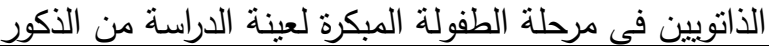

\begin{tabular}{|c|c|c|}
\hline المستّوى الاقَتصادي & \multicolumn{2}{|c|}{ المتغيرات } \\
\hline ***, $0 \leqslant V-$ & معامل الارتباط & \multirow{2}{*}{ الضغوط الجسمية } \\
\hline$\cdot, \cdots \varepsilon$ & الدلالة المعنوية & \\
\hline., .77 & معامل الارتباط & \multirow{2}{*}{ الضغوط النفسية } \\
\hline$\cdot, \Lambda$ & الدلالة المعنوبة & \\
\hline$\cdot, \cdot 1 \leq$ & معامل الارتباط & \multirow{2}{*}{ الضغوط التواصلية } \\
\hline$\cdot, 9$ & الدلالة المعنوية & \\
\hline$\cdot, .91$ & معامل الارتباط & \multirow{2}{*}{ الضغوط السلوكية } \\
\hline$\cdot, 7$ & الدلالة المعنوبة & \\
\hline$\cdot,+19-$ & معامل الارتباط & \multirow{2}{*}{ الضغوط الاجتماعية } \\
\hline$\cdot, \wedge \wedge \wedge$ & الدلالة المعنوية & \\
\hline$\cdot, Y$ & معامل الارتباط & \multirow{2}{*}{ الضغوط الاقتصادية } \\
\hline$\cdot$, YqV & الدلالة المعنوية & \\
\hline$\cdot, 1 \leq V-$ & معامل الارتباط & \multirow{2}{*}{ إجمالي المقياس } \\
\hline$\cdot, 0$ & الدلالة المعنوبة & \\
\hline
\end{tabular}


يوضح الجدول السابق نتائج العلاقة الإرتباطية بين الضغوط البيئيه والمستوى الاقتصادي على الأطفال الذاتويين في مرحلة الطفولة المبكرة لعينة الدراسة من الذكور

ه توجد علاقة إرتباطية عكسية ذات دلالة معنوية عند مستوى معنوية (0., •) بين الضغوط الجسمية والمستوى الاقتصادي على الأطفال الذاتويين في مرحلة الطفولة المبكرة لعينة

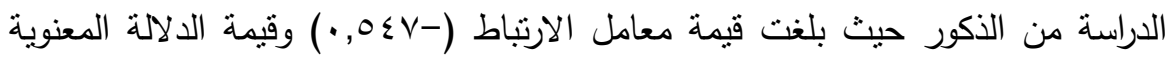

$$
\cdot(\cdot, \cdots \varepsilon)
$$

ه بينما لم يكن هناك علاقة إرتباطية ذات دلالة معنوية عند مستوى معنوية (0., •) بين باقي أبعاد الضغوط البيئيه وإجمالي الضغوط والمستوى الاقتصادي على الأطفال الذاتويين في مرحلة الطفولة المبكرة لعينة الدراسة من الذكور. جدول (•): العلاقة الإرتباطية بين الضغوط البيئيه والمستوى الاقتصادي على الأطفال

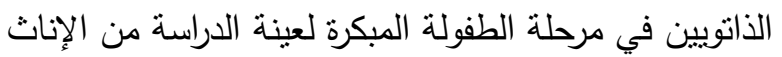

\begin{tabular}{|c|c|c|}
\hline المستوى الاقتصادي & \multicolumn{2}{|c|}{ المتغيرات } \\
\hline$\cdot, \cdot \vee \varepsilon$ & معامل الارتباط & \multirow{2}{*}{ الضغوط الجسمية } \\
\hline$\cdot, \mathrm{V}$ & الدلالة المعنوية & \\
\hline$\cdot, 11$ & معامل الارتباط & \multirow{2}{*}{ الضغوط النفسية } \\
\hline$\cdot, 7$ & الدلالة المعنوية & \\
\hline$\cdot, 11 \pi$ & معامل الارتباط & \multirow{2}{*}{ الضغوط التواصلية } \\
\hline$\cdot, 7$ & الدلالة المعنوية & \\
\hline • & معامل الارتباط & \multirow{2}{*}{ الضغوط السلوكية } \\
\hline$\cdot, 1$ & الدلالة المعنوية & \\
\hline$\cdot, 11 \mathrm{~V}$ & معامل الارتباط & \multirow{2}{*}{ الضغوط الاجتماعية } \\
\hline$\cdot, 7$ & الدلالة المعنوية & \\
\hline$\cdot, Y \cdot I$ & معامل الارتباط & \multirow{2}{*}{ الضغوط الاقتصادية } \\
\hline$\cdot, r$ & الدلالة المعنوية & \\
\hline$\cdot, 1 \wedge \wedge$ & معامل الارتباط & \multirow{2}{*}{ إجمالي المقياس } \\
\hline$\cdot, \varepsilon$ & الدلالة المعنوية & \\
\hline
\end{tabular}

يوضح الجدول السابق نتائج العلاقة الإرتباطية بين الضغوط البيئيه والمستوى البهن

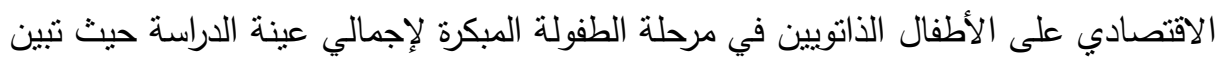


عدم وجود علاقة إرتباطية ذات دلالة معنوية عند مستوى معنوية (0. . •) بين الضغوط البيئيه والمستوى الاقتصادي على الأطفال الذاتويين في مرحلة الطفولة المبكرة لعينة الدراسة من عنديه الإناث.

تفسير نتائج الفرض الأول: والذى ينص على أنه "توجد علاقة ذات دلالة احصائية بين تأثير الضغوط البيئيه والمستوى الاقتصادى على الأطفال الذاتويين فى مرحلة الطفولة المبكرة"، ولم

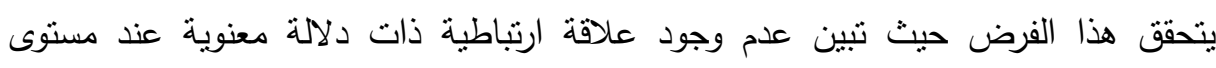

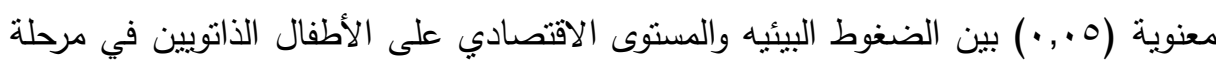
الطفولة المبكرة لإجمالي عينة الدراسة.

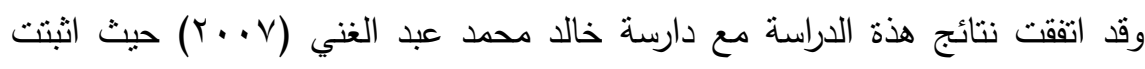

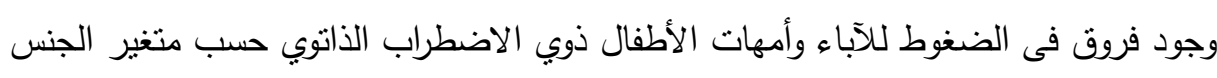

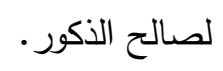
وقد اختلفت نتائج هذة الدراسة مع دراسة Johnso ، Frenn، Feetham،Simpson

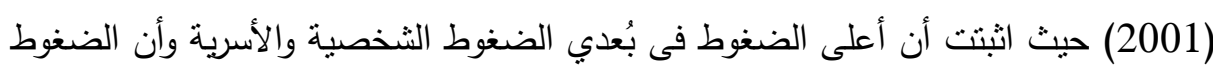
ارتبطت بدرجة أقل مع الصحة الجسمية.

\section{تموسياهت الدراسما}

\section{التوصيات التطبيقية:}

ا. الاكتشاف المبكر والعلاج الفعال والمتابعة المستمرة للاطفال الذاتويين ووضع برامج

تعليمية للعاملين مع الأطفال الذاتوبين للتعرف المبكر على المرض وكيفية التعامل معه.

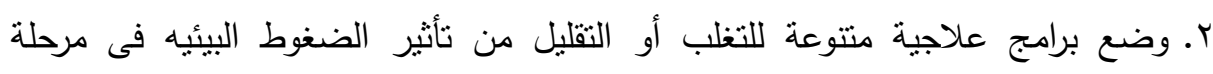
الطفولة المبكرة. r. وضع برنامج علاج بيئى سلوكى للتقليل من تأثير الضغوط البيئيه مع التركيز على البعد الاجتماعي الاقتصادي. 
ع. ضرورة توعية آباء وأمهات الأطفال الذاتويين وذويهم بتأثير الضغوط البيئيه وكيفية التقليل منها والتعامل معها.

0. اعداد ملفات خاصة لكل طفل ذاتوى يدون فيها كل معلومة تتعلق به وبأسرته حتى يسهل

$$
\text { التعامل معه وإعداد البرامج التى تلائمه. }
$$

7. اعداد برامج ارشادية لآباء وأمهات الأطفال الذاتويين بكيفية التعامل والرعاية الملائمة التى لتى

$$
\text { تتاسب الطفل الذاتوي. }
$$

V. التوسع فى المراكز والمؤسسات التي تقدم خدماتها لذوي الاحتباجات الخاصة ومتعددي

^. ضرورة اثتراك الأبوين مع الروضة فى تطوير خطة مناسبة للتنخل المبكر فى سبيل

$$
\text { مواجة المشكلات الاجتماعية التى تتجم عن هؤلاء الأطفال. }
$$

المقترحات البحثية: توصي الباحثة باجراء مزيد من الدراسات على الأطفال الذاتوبين وخاصة فيما يتعلق بتأثنر الضغوط البيئيه عليهم. وذلك من خلال:1. عمل دراسات عن الأطفال الذاتويين نتشمل أكبر عدد من الحالات مع الأخذ في الاعتبار الاختلاف فى المرحلة العمرية والتتوع فى المستويات الاقتصادية والاجتماعية فى مصر .

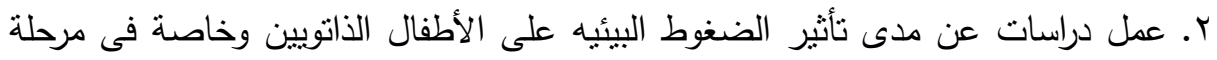

$$
\text { الطفولة المبكرة. }
$$

r. عمل دراسات فى العوامل البيئيه للاطفال الذاتوبين والتى لها تأثير عليهم.

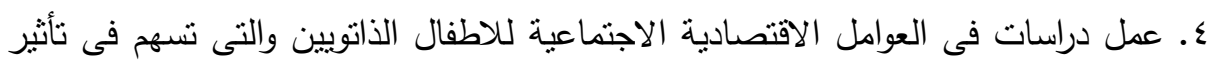

$$
\text { الضغوط البيئيه عليهم. }
$$

๑. اجراء دراسة مسحية للاطفال المصابون بالاضطراب الذاتوى فى جمهورية مصر العربية، لمعرفة مزيد من التفاصيل والمعلومات عن الاضطراب الذاتوب، وتقديم خدمة أكثر فاعلية للطفل الذاتوى و المهتمين به. 
مجلة العلوم البيئية

معهد الدراسات والبحوث البيئية - جامعة عين شمس لئه

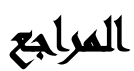

أبو سعد، أحمد الغرير (9 . . r): الارشاد الزواجى الأسرى، عمان، دار الثرق للنشر والتوزيع. أحمد النجار (ך ץ): التوحد واضطراب السلوك، عمان، الاردن، دار المشرق الثقافى.

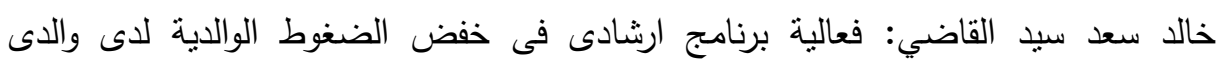

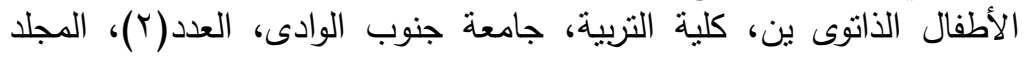

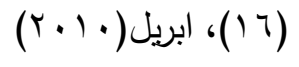

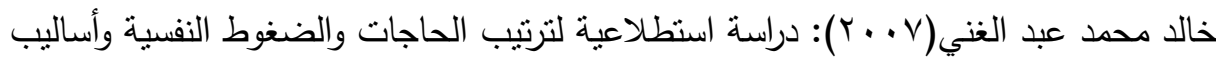

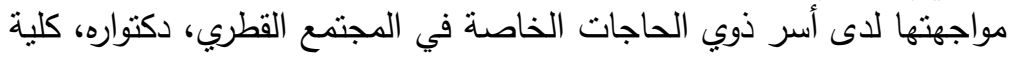
التربية، جامعة قطر التر

راف الله بو شعراية: دراسة الضغوط النفسية وعلاقتها بالتوافق الأسرى لدى آباء وأمهات أطفال

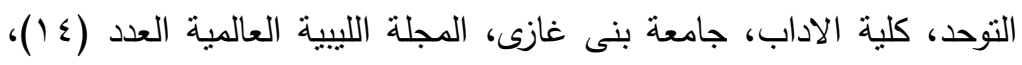

$$
\text { فبراير (r. IV ) }
$$

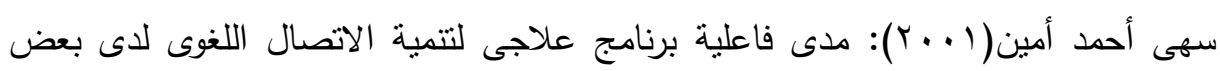

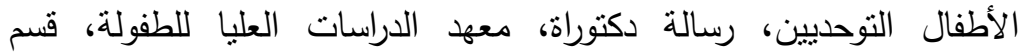

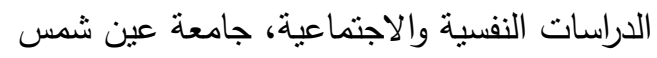

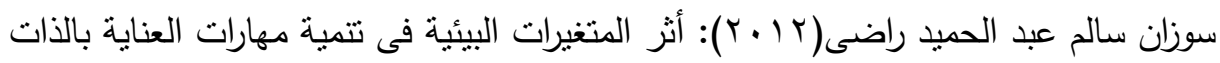

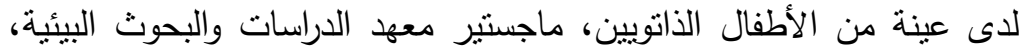

$$
\text { قسم العلوم الانسانية البيئية }
$$

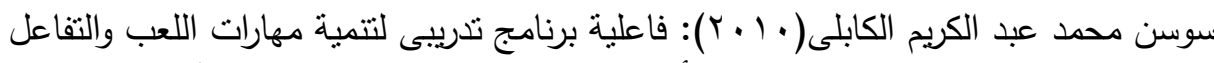

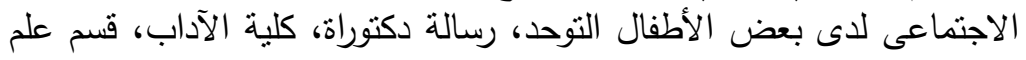

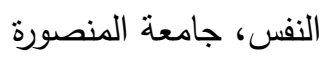

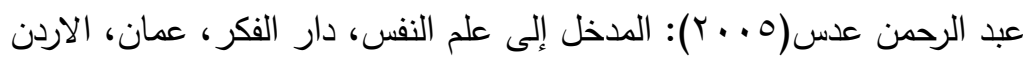

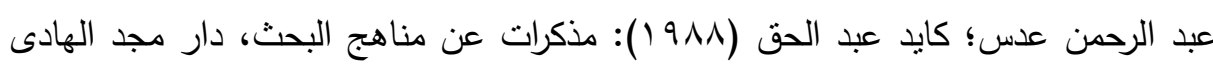

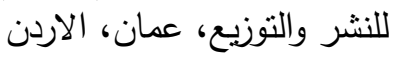

عبد الرحمن محمد السيد(991 (1): نظريات فى الثخصية، دار قباء للطباعة والنشر والتوزيع،

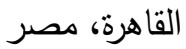


عبد العزيز السيد الثخص(ب ا • r): مقياس المستوى الاجتماعي الاقتصادي للأسرة، مكتبة الأنجلو المصرية، الترقيم الدولي: 6000000633

عبد الهادي الجوهري(99V (19): أصول علم الاجتماع، دار المعرفة الجامعية، القاهرة

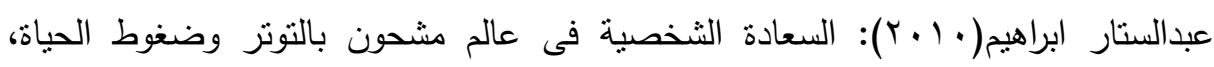

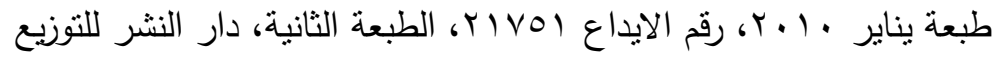

على ماهر خطاب: مناهج البحث في العلوم النفسية والتربوية والاجتماعية، بدون دار نشر،

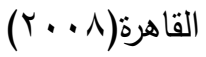

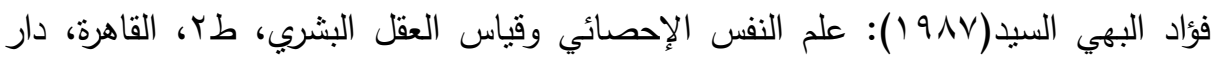

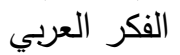

لويس مليكة(991 ()): الاعاقات العقلية والاضطرابات الارتقائية، مكتبة النهضة العربية، القاهرة

محمد أحمد خطاب(0 · ب): سيكولوجية الطفل التوحدي: تعريفها تصنيفها اعراضها أسبابها

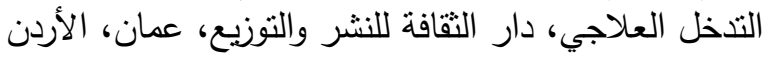

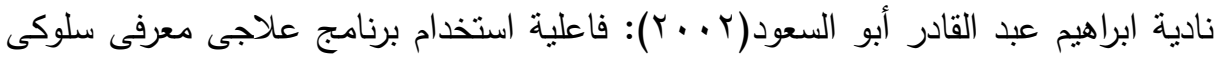

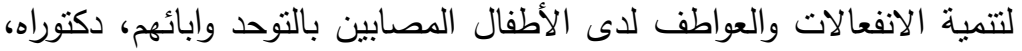

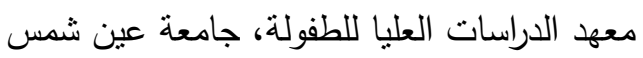

عمر النعاس: الضغوط المهنية وعلاقتها بالصحة النفسية، القاهرة، منشورات جامعة

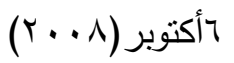

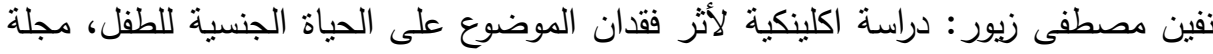

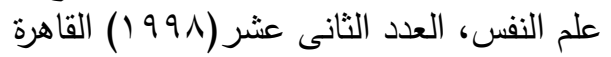

هدى أمين(999 (19): الدلالات التشخيصية للأطفال المصابين بالأوتنزم، رسالة ماجستير، كلية الآداب، قسم علم النفس، جامعة عبن شمس.

وليم الخولى(Y7 (97) ): الموسوعة المختصرة فى علم نفس الطب العقلي، القاهرة، دار المعارف.

Hall, H. (2008): The relationship Among Adaptive Behaviors of Children with Autism Spectrum Disorder, Their Family Support Networks parental stress, And Parental Coping, Dissertation, The University of Tennessee, Health Science Center.

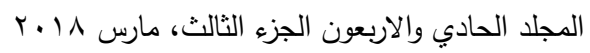




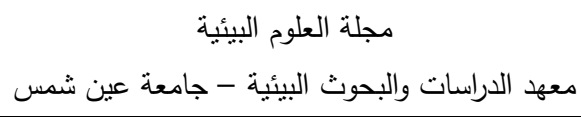

Hart, A. (2004): Origin of Stress, Depression \& Anxiety in Parents of Autistic Children \& the Impact on the Family: A Quantitative and Qualitative Study (Doctoral dissertation, University of Wollongong).

Lazarus, R. (1966): Stress and Emotion a new synthesis. Jan., 12 $2^{\text {th }}, 2013$

Simpson, Johnson, Feetham, Frenn (2001): Stress in UK Families Conducting Intensive Home-Based Behavioral Intervention for Their Young Child with Autism, Journal of Autism and Developmental Disorders.

\title{
ENVIRONMENTAL STRESSES AND THEIR IMPACT ON A SAMPLE OF EARLY CHILDHOOD AUTISTIC CHILDREN
}

Shafeeq, J. ${ }^{(1)}$; Ibrahim, Hala, A. ${ }^{(2)}$ and Al-Sayed, Doaa, I.

1) Institute of Graduate Studies for Children, Ain Shams University

2) Institute of Environmental Studies and Research, Ain Shams University

\begin{abstract}
The study aimed at detecting the effects of environmental stress on children in early childhood.

The researcher used the descriptive descriptive approach. The study sample included 50 children and children suffering from autism disorder, but not accompanied by any mental disability or other organic problem. The sample was collected from private centers in Cairo Governorate, as the center of integration Ghamra and the center of integration in the seventh district of Nasr City.
\end{abstract}

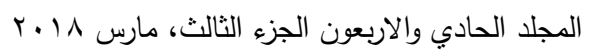


The measure of the effect of environmental pressures on autistic children (the researcher's preparation) and the socio-economic scale of the family (prepared by Abdul Aziz al-Hafs 2013) was used.

In light of the objectives of the present study and its hypotheses, the following statistical methods were used:

The data were extracted through the statistical program known as Statistical Package for Social Sciences. The statistical analysis using the computer through the statistical package software SPSS V.20, and this step -data collection- a preliminary step to tabulate the data, and through it was the following:

Stability test through the Cronbachs Alpha laboratory to test the stability of the study variables. Test the validity of internal consistency through Pearson correlation coefficient between the dimensions of the study and the total scale. Data descriptive statistics by scheduling data in tabular form (mean and standard deviation) of study variables. To establish the correlation relations with the Kendal correlation coefficient to verify the validity of the hypotheses of the study. Simple regression analysis to study the effect of environmental stress on early childhood autistic children. Multiple regression analysis to study the effect of environmental stress on early childhood autistic children.

The study shows the following results: There is no relationship with statistical correlation between the impact of environmental pressures and the economic level on the children of the autistic in early childhood and there is a correlation between the physical pressures and the economic level in favor of males. There is no relationship with the correlation between the statistical impact of environmental pressures and social level on the children of autis $m$ in early childhood. There are no statistical differences between male and female males on the scale of the effect of environmental pressures on children in early childhood. There are no differences of statistical relativity between males and females at the economic level of the early childhood autistic children. There are no statistically significant differences between males and females at the social level of early childhood autistic children.

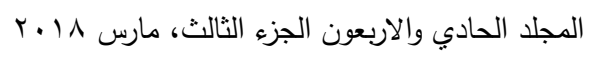




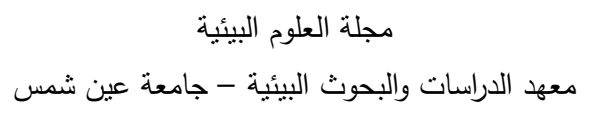

It is recommended that further studies be conducted on autistic children, especially with regard to the impact of environmental pressures on them, through: Studies on autistic children include the largest number of cases, taking into account differences in age and diversity in economic and social levels in Egypt. Studies on the impact of environmental stress on autistic children, especially in early childhood. Studies of the environmental factors of the autistic children, which have an effect on them.

Key words: Environmental pressures, Autistic disorder, Early childhood. 